\title{
Editorial
}

\section{How to choose a proper journal for publication?-Credential assessment: A review}

\author{
Dhiraj B Nikumbh ${ }^{\circledR}$,* \\ ${ }^{1}$ Dept. of Pathology, SBH, Government Medical College, Dhule, Maharashtra, India
}

\section{A R T I C L E I N F O}

Article history:

Received 27-02-2022

Accepted 02-03-2022

Available online 04-03-2022

\begin{abstract}
This is an Open Access (OA) journal, and articles are distributed under the terms of the Creative Commons Attribution-NonCommercial-ShareAlike 4.0 License, which allows others to remix, tweak, and build upon the work non-commercially, as long as appropriate credit is given and the new creations are licensed under the identical terms.
\end{abstract}

For reprints contact: reprint@ipinnovative.com

\section{Dear researchers,}

There is big and endless list of questions in the mind of authors regarding selecting a proper journal for his/her guanine work in academics. The list is big, but can be summarized as which is the best suitable journal?- in view of discipline, target audience, acceptance, rejection etc. Waiting period for the publication?- issues, pending articles and so on. Is it is legitimate or predatory journal? Journal helps in my career anyways? Is there are funding opportunities? Increased or decreased. ${ }^{1-5}$

The ICMJE recommends that authorship be based on the following 4 criteria: $^{5}$

Substantial contributions to the conception or design of the work; or the acquisition, analysis, or interpretation of data for the work; Drafting the work or revising it critically for important intellectual content; Final approval of the version to be published; Agreement to be accountable for all aspects of the work in ensuring that questions related to the accuracy or integrity of any part of the work are appropriately investigated and resolved. ${ }^{5}$

\section{Introduction}

Best choice of journal can enhance the impact of your work and your reputation hence the verb as Publish or Perish. More than 80,000 academic, peer reviewed English

\footnotetext{
* Corresponding author.

E-mail address: drdhirajnikumbh@gmail.com (D. B. Nikumbh).
}

language journals currently active as of July 2019 and 30,000 of these journals are classified under Medicine and Health. $^{1-3}$

Guidelines and recommendations are there as follows, one can through these links for the details asICMJE-International committee of Medical Journal Editors (2016), NIH-the National Institute Of Health (2017), COPE-Committee on publication ethics, WAME-The World association of Medical editors. ${ }^{5-8}$

All the reputed journals endorse guidelines as per above guidelines and these can be seen in detail on the respective websites. There is no reliable list of good vs bad journals, nor there is an automated decision-aid tool to use for identifying journals for publication. ${ }^{1-4}$

'Authors have a responsibility to evaluate the integrity, history, practices and reputation of the journals to which they submit the manuscript'.by ICMJE/NIH. ${ }^{5,6}$

$1^{\text {st }}$ step is to - Analyze all the pros and cons of many journals is the crucial step. Shortlist among them into $3 / 5$ journals with the help of mentor, senior or expert colleagues. Best way is to go through the journal websites to know more about them. It gives and satisfies many of the researcher's questions for the selection of journal for publication?. ${ }^{1,2}$ 


\section{List of factors for selecting the right journal for publication $^{1-4}$}

Scientific rigor /Aim and scope of the journal

Authors should visit the Website, read the 'about the journal', narrow down the list. If aim is fulfilled related to your topic, go ahead and if not then turn in opposite direction-helpful in narrowed to your research. Furthermore read the few abstracts or articles of that journal to include in your shortlist category.

\section{Editorial quality}

Editorial, titles and abstracts provides clue of quality of the journal. Misspellings, grammar and punctuation errors, lack of clarity, cohesion in writing are indicative of lack of editorial insight and reviewer commitments. These are the clues and warning sign of not appropriate journal for your work.

Editorial board members (EIC)-Review of journal editorial board can reveal valuable insights to as to the quality of a journal. Editorial board members should be known established experts in the field related to aim and scope of the journal. Contact information, affiliations, institutions with appropriate academic credentials should be available on website. EIC and other members contribute frequently and thoughtful editorials for the issue add a special significance.

\section{Peer review process}

Transparency of peer review process is a benchmark of journal quality. Articles in Peer reviewed journals enjoy more respect among academic and scientific fraternity. Types of review are single blind, double blind or open review. Feedback of the reviewers can be accepted or rejected by the editor adding value to these peer reviewed journals.

\section{Journal impact factor (JIF)}

JIF is still the default method to analyze the quality and reputation of the journal. It displays number of total citations of articles in last 5 years to support the journal articles. Important factor for to get grants, jobs and promotions if the author article is published in journal with high impact factor. However, 'Authors should pick the target journals based on relevance an scientific rigor and quality,not on spurious impact factors' or Metrics methods tool.

\section{Indexing of the journals}

Authors want their research to be discoverable and read by others. Proper indexing adds to their reputations in term of broad coverage in reputed databases.

National medical commission/NMC indexing agencies of journals (effective from 16.2.2022). ${ }^{9}$ Medline, Pubmed central, Citation index, Science citation index expanded, Embase, Scopus, DOAJ-Directory of open access journals. ${ }^{9}$

It's better to check the respective list and confirm the desired journal listed in it.

PubMed Central (PMC) is a free digital archive database of full-text scientific literature in biomedical and life sciences at the U.S. National Institutes of Health (NIH), developed and managed by NIH's National Center for Biotechnology Information (NCBI) in the National Library of Medicine (NLM). PubMed Central provides openly available peer-reviewed scientific research. In PMC there will be a link to the full text article published on Science Direct, accessible by clicking the header above the article title. $^{5-8}$

Pubmed -is a resource that aggregates citations from MEDLINE,PMC and other resources from NCBI bookshelf. PMC- is a free archive of full-text journals articles. MEDLINE- subset of Pubmed, is a journal citation database from the National Library of Medicine (NLM). ${ }^{1-4}$

Hence better to check \&verify indexing status using a bibliographic and citation database.

PubMed is a citation database. PubMed does not display the full text of articles but instead comprises more than 25 million citations for biomedical literature from MEDLINE, life science journals, and online books. Citations may include links to full-text content from PubMed Central and publisher web sites such as Science Direct. Publishers participating in PubMed electronically submit their citations to National Center for Biotechnology Information (NCBI) prior to or at the time of publication. PubMed also provides links to biological resources, consumer health information, research tools, and more. There may be a charge to access some text or information. ${ }^{5-8}$

\section{Accepetance rate and publication time}

Check for the acceptance rate of the journal from the website and their lower acceptance rate confirm their worthiness. Seasoned researchers know that for good manuscript to be published in reputed journal take 9 to 12 months. The optimum time limit for the rejection is 4 to 6 weeks. Sometimes rejection after a prolong time can create a problem to researchers academically. Remedy is author should wait for special editions -more chances to accept.

\section{Journal reputation \& reach of journals}

Reputation depends on the publisher or societal organization that sponsors the journal. It should be clear and transparent model. It is imperative for your article to reach a broad $\&$ global audience by the boom of open access (OA) movement.

Open access-Readers pay nothing to read the paper. The author may pay article processing charges. Closed accessThe author does not pay to publish as fees recovered by individual/institutions after paying or by professional 
membership.

\section{Ethics,Author rights and copyright}

Reputed journals endorse guidelines and best practices for publishers as ICMJE, COPE \&WAME. Autrhors should search for the website of the journal. Plagiarism scan (iThentcate, Turnitin, Plagiscan), conflict of interest, informed consent, institutional ethical board permission, confidentiality etc. Copyright is a bundle of rights that allow authors to use, disseminate, display or modify the work in any medium. Transparency of copyright polices for authors is indicative of a quality journal.

\section{Check for journals restrictions}

Most reputable article may be rejected due to its beyond the scope of the journal, hence first check aim and scope and instructions to authors.Other limitations are -word count, type of article, article processing charges etc.

\section{Journal operations}

The aim and scope, editorial board members, instructions to authors, journal contact information should be available and easy to find.

An irregular publication schedule, excessive advertising, missing or sporadic issue are indicative of unstable journal management. DOI-digital object identifier is assigned to articles are not?, ISSN-International Standard Serial Number -online or print is assigned to the journal?, Publication schedule-monthly/ quarterly or yearly, so that authors can plan accordingly.

\section{Legitimate vs Predatory journals}

Consultations with mentors and senior expert colleagues definitely helpful for early career authors to decide between legitimate vs predatory. ${ }^{8}$ First 9 points with checklist will be helpful in this aspect of quality. Don't fall prey /victim of predatory journals by phishing and repeated mails of false promises. ${ }^{8}$

\section{Warning Signs ${ }^{1-3}$}

Archaic salutation-ancient/obsolete titles, Hyperbolic language in email-exaggerated, Poor grammar or misspellings, Excessive use of exclamation marks, Promises of swift review or immediate conference abstract acceptance, Journal aim and scope and conference topic is not germane to your area of research. The publisher icon/logo is similar to an established journal. No credentials for the editor, editorial staff, and/or editorial board members. Indexing status for the journal is noted as PubMed ${ }^{\circledR}$ or Google Scholar or a directory. Vague impact score for the journal or claims that the journal is high impact. The publisher or conference organizer is unfamiliar. Journal or conference title is similar to an established journal or conference. Inappropriate images or ads/animations on website. Inconsistent publication or conference history/schedule. No ISSN for the journal. No DOI for the publications etc., are the warning signs.

\section{Conclusion}

Authors should have to look for journal website carefully. Shortlist 3 to 5 medical journals. Later finalize one after researching the goal. Carefully look for the warning signs. Think - check - submit ${ }^{1}$ is the motto of the final submission of the journal for publication.

\section{Acknowledge}

Special thanks to IESRF TEAM. The whole team of innovative publication, New Delhi for their hard work, dedication and perseverance with constant increasing growth in academic field.

\section{Conflict of Interest}

None.

\section{References}

1. Suiter AM, Sarli CC. Selecting a Journal for Publication: Criteria to Consider. Mo Med. 2019;116(6):461-5.

2. Available from: https://thinkscience.co.jp/en/articles/choosing-theright-journal.

3. 101 Tips from JournalPrep.com. Available from: https://www journalprep.com/FILES/101Tips.pdf.

4. Beall J. Predatory publishers are corrupting open access. Nature

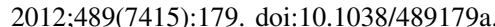

5. Available from: http://www.icmje.org/recommendations/browse/rolesand-responsibilities/defining-the-role-of-authors-and-contributors. html.

6. Available from: https://www.nih.gov/research-training.

7. Available from: https://publicationethics.org/guidance/Flowcharts.

8. Available from: http://wame.org/policies.

9. The gazette of India: Extraordinary ,part II-SEC.4 Teachers Eligibility Qualifications(TEQ) in medical institutions regulations, dated 14th Feb,2022.

\section{Author biography}

Dhiraj B Nikumbh, Associate Professor (1) https://orcid.org/0000-00027440-9007

Cite this article: Nikumbh DB. How to choose a proper journal for publication?-Credential assessment: A review. IP Arch Cytol Histopathology Res 2022;7(1):1-3. 